\title{
Making Sense of Settlement: Class Transformation, Cultural Struggle, and Transnationalism among Mexican Migrants in the United States
}

\author{
ROGER ROUSE \\ Department of Anthropology \\ 1054 LSA Building \\ University of Michigan \\ Ann Arbor, Michigan 48109
}

Mexicans have been migrating to the United States in significant numbers for more than a hundred years. From the outset, the great majority of this migration has been temporary and circular. Contrary to popular opinion, people have generally come for periods ranging from a few months to a couple of years and then returned home (Cockcroft 1982; Cornelius 1979). Since the late 1960 s, however, there has been a marked growth in settlement. While temporary migration continues to predominate, it has become increasingly common for people to stay for extended periods and to establish new homes north of the border (Chavez 1988; Cornelius, in press).

How should we understand the experiences of these recent settlers? What kinds of influence have they faced, and how have they responded? More importantly, how should we theorize and conceptualize their relationship to the contexts in which they have lived? For more than forty years, the ethnographically based literature on Mexican migration has been dominated by two closely related tendencies. ${ }^{1}$ First, migration in general has been analyzed

1 There is surprisingly little ethnographically based literature that deals directly with Mexican migration to the United States and even less that draws on fieldwork conducted north of the border. Until the 1980 s, much of the work empirically most relevant to an understanding of Mexican settlement was found in studies of Chicano neighborhoods that contained at least some settlers and much of the work conceptually and theoretically most relevant was found in studies of migration within Mexico. My introductory remarks refer to all three kinds of literature. It is important to point out that I am concerned to identify general tendencies and trends in these related arcas over a period of almost half a century. I cannot do justice to the subtlety of particular studies or to evolving differences and debates. For an overview of work on Mexican migration to the United States prior to the 1980s, see Kemper (1979); for reviews of anthropological work on Chicanos see Romano-V. (1968, 1970), Rosaldo (1985), and Vaca (1970a,b); and for a review of general anthropological work on migration, informed by a detailed knowledge of the Mexican literature, see Kearney (1986). 
mainly in bipolar terms (Uzzell 1976) as a move between essentially autonomous communities and, within this framework, settlement has been treated as a process in which people steadily shift their focus of attention and the locus of their principal social ties from one community to another. ${ }^{2}$ Second, the attitudes and practices of those involved have been understood primarily from a neofunctionalist perspective as more or less effective forms of adaptation to a new environment. ${ }^{3}$

There have, of course, been important changes in the literature dealing with Mexican migration and settlement. Most notably, it has been common since the late 1960s to challenge earlier studies in which people's problems were attributed primarily to the difficulties they experienced in modifying their existing values and beliefs ( $c f$. Romano-V. 1968, 1970; Vaca 1970a,b). Environments once deemed homogeneous and beneficent have been reconstituted as differentiated, exploitative, and oppressive; people once treated as passive and bound by custom have been reconceptualized as active and creative agents; and responses once considered maladaptive have been reinterpreted as rational reactions to structurally conditioned problems. No longer seen as victims of their own cultural inertia, settlers have increasingly been lauded for developing effective forms of coping under difficult conditions. ${ }^{4}$

Yet the literature remains problematical in several respects. In the first place, the growing emphasis on creative adaptation has been accompanied by a marked retreat from culture. Responding to the fact that culturally oriented analyses often seemed to "blame the victims," scholars have come to understand migrants' experiences increasingly in behavioral terms as manifest responses to particular configurations of opportunity and constraint. We thus know very little that is analytically significant about the ways in which recent settlers have made sense of their lives. At the same time, the emphasis on a bipolar framework has obscured the ways in which many settlers during the

${ }^{2}$ This approach is most clearly manifest in studies that compare sociocultural forms in the destination community with those manifest in the community, or general area, from which the settlers came. For examples from work on migration within Mexico, see Butterworth (1962), Kemper (1977), and Lewis (1952). For examples from work on Mexican settlers and Chicano neighborhoods in the United States, see Achor (1978), Horowitz (1983), Humphrey (1944), Madsen (1964), Rubel (1966), and Thurston (1974).

${ }^{3}$ For a general review written from this perspective, see Graves and Graves (1974). A particularly clear statement of its significance in the study of a Chicano neighborhood can be found in Achor (1978: 166-176). For examples of its use in the study of migration within Mexico, see Butterworth (1962), Hendricks and Murphy (1981), Kemper (1977), Lomnitz (1976, 1977), and Ugalde (1974). Examples of its use in the study of Mexicans migrating to and living in the United States can be found in Alvarez (1987), Alvirez and Bean (1976), Baca and Bryan (1983), Carlos (1975), Humphrey (1944), and Rubel (1966).

${ }^{4}$ See, for example, Alvarez (1987), Alvirez and Bean (1976), Carlos (1975), Hendricks and Murphy (1981), Kemper (1977), Lomnitz (1977), and Ugalde (1974). During the last decade, this approach has moved in a more Malinowskian direction with a growing emphasis on treating migration itself as an "adaptive household strategy." Examples in the Mexican context include Dinerman (1978) and Wood (1981); for a critical response, see Rouse (1989b). 
last two decades have managed to maintain active involvements with the people and places they have left behind and, in so doing, have often helped create new kinds of communities that span the international border. And finally, the emphasis on adaptation has made it difficult to conceptualize and identify the contradictions and potential conflicts that are entailed in the classrelated dimensions of settlement.

In this article, I shall outline an approach that addresses all three problems. Giving particular emphasis to the ways in which recent settlers have evaluated and interpreted their lives, I shall argue that we should view their understandings from a theoretical perspective attentive to the cultural struggles associated with class transformation and that we should view these struggles within a conceptual framework sensitive to the emergence of transnational forms of organization. That is, while emphasizing the importance of approaching settlement from a transnational perspective, I shall argue that it is equally important to approach transnationalism from a perspective attentive to the interplay of culture, class, and power.

To give these general claims a particular point of reference, I shall draw on my knowledge of a single case, the migration that has taken place since the early 1940s between the municipio (or "county") of Aguililla in the westcentral region of Mexico and Redwood City, an urban jurisdiction in northern California. More narrowly, I shall focus on the experiences of men who spent extended periods in Redwood City between the late 1960s, when an Aguilillan community began to emerge there on a significant scale, and the mid1980s, when I concluded my research. More narrowly still, I shall develop my argument through an account that concentrates on just two men, brothers whom I shall refer to as "Carlos" and "Antonio." While the evidence that informs my analysis comes from work with a large and varied group of settlers, I hope in this way to show how the cultural politics of class transformation and the workings of transnationalism have been played out concretely in the details of people's daily lives.

Before proceeding, I should emphasize two points about this analysis. First, its basic elements are by no means novel. In theoretical terms, it owes a great deal to E.P. Thompson's magisterial study of the making of the English working class (Thompson 1966) and to the varied treatments of the relationship between culture, power, and practice in the work of Raymond Williams

\footnotetext{
${ }^{5} \mathrm{My}$ understanding of Aguilillan migration is based largely on twenty-seven months of fieldwork carried out between October 1982 and December 1984. During this period, I spent almost equal amounts of time in Aguililla and Redwood City. To minimize the threatening nature of my research, I did not carry out a formal survey but relied instead on participant observation and the collection of oral histories. It is important to appreciate the historical specificity of this research. Since its completion, the context in which Aguilillans operate has been significantly altered by passage of the Immigration Reform and Control Act of 1986 and by dramatic changes in the politics and economics of the municipio (Ramírez 1988; Reding 1990). It is to encourage a sense of historical specificity that I refer to the experiences of Aguilillans in the past tense
} 
(1977), Michel Foucault (1979, 1983), Pierre Bourdieu (1977) and Michel de Certeau (1984). Moreover, in stressing the significance of transnational arrangements, it parallels important developments made recently both within the literature on Mexican migration and beyond. ${ }^{6}$ My aim is simply to bring these elements together in a manner that illustrates their capacity for mutual illumination.

The second point to stress is that, in concentrating on Aguilillan men, I do not mean to deny the importance of women's contributions to the process of settlement. Nor do I mean to suggest, more generally, that men forged their attitudes and practices in isolation. The two sexes influenced one another in numerous ways and their lives were inextricably linked. At the same time, however, the cultural and political contexts in which they operated meant that their experiences were significantly different. My focus on the lives of men reflects both a recognition of these differences and a more general concern to approach the experience of settlement in a manner that is properly attentive to the specificities of gender.

Having made these points, I shall begin by providing some preliminary information on the history of Aguilillan migration to the United States and on the particular trajectories that Carlos and Antonio described.

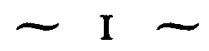

The municipio of Aguililla is located in the southwest corner of the state of Michoacán in a mountainous region known locally as the Costa Sierra. ${ }^{7}$ Sandwiched between the Tepalcatepec Valley to the north and the Pacific Ocean to the south, this region was for many years a marginal and isolated zone remote from major centers of power and wealth in the interior of the country. In the early 1940s, the municipio was dominated by a way of life organized around small-scale ranching and peasant farming, one in which people strove locally to create and maintain their own independent, familyrun operations. At that point, however, Aguilillans began migrating in significant numbers to the United States and, over the next four decades, the municipio came increasingly to serve as a nursery and nursing home for people working in wage-earning jobs north of the border.

${ }^{6}$ The concept of multilocational communities was first developed in the Mexican context during the 1970 s in studies dealing with internal migration. A seminal analysis by Roberts (1974) on migration in Peru and Guatemala, itself apparently influenced by earlier work in Africa, was followed by articles on Mexico from Lomnitz (1976) and Uzzell (1976). More recently, the concept has been elaborated in studies of migration to the United States by Baca and Bryan (1983), Kearney (1986), Kearney and Nagengast (1989), Massey et al. (1987), and Mines (1981). My own contributions appear in Rouse (1989a, 1991). Parallel developments regarding other migrations are summarized by Glick Schiller, Basch and Blanc-Szanton (this volume).

${ }^{7}$ A fuller version of this account can be found in Rouse (1989a). 
For the first two decades, the great majority of the migration was temporary and circular. The most common pattern was one in which men left their families in the municipio to work seasonally in agricultural jobs in the rural southwest. The numbers migrating in any one year were relatively low and, in aggregate terms, the impact of migrants' earnings was limited. From the mid1960s onwards, however, the level of migration rose significantly and the municipio's economy became increasingly dependent on the influx of dollars. Moreover, the patterns of movement changed. A growing proportion of Aguilillans headed for urban destinations, where it was easier to find employment on a year-round basis. Women and children began to migrate in greater numbers. And, reflecting broader trends, it became steadily more common for people to settle north of the border.

As settlement increased, Aguilillans rapidly established a series of satellite communities in the United States. From the late 1960s, by far the largest of these was in Redwood City, an urban jurisdiction on the northern edge of California's famous "Silicon Valley." In the early 1980s, when there were roughly 26,000 people living in the municipio, there may have been as many as 7,000 Aguilillans (including their U.S.-born children) in the Redwood City area. As a function of the growing restrictions on legal entry to the United States, many were undocumented. Despite this difficulty, however, people found jobs throughout the valley, almost invariably working in the region's burgeoning secondary labor market. Although some were employed in light assembly, the great majority worked in the service sector. Men found jobs as gardeners, landscapers, janitors, and dishwashers, while women who earned wages generally did so as hotel cleaners, child-minders, and domestic servants.

Beginning in the early 1940s, then, the population of the municipio experienced a dramatic and accelerating dispersion. But more was involved than a simple change in spatial distribution. At the same time, and in some respects more crucially, Aguilillans underwent a major shift in the ways in which they made a living. In general terms, they moved from an emphasis on various forms of petty production to a growing dependence on wage-labor; more specifically, they came increasingly to rely not only on working for wages but on selling their labor power as a carefully calibrated and readily alienable commodity within the context of contractual relations. That is, put simply, they underwent a process of "proletarianization." Some experienced this shift without leaving the municipio, but for most people it was an integral part of their first trip to the United States.

\footnotetext{
${ }^{8}$ Redwood City is located in San Mateo county, on the western side of the San Francisco Bay, roughly half way between San Francisco and San Jose. Many analysts locate "Silicon Valley" entirely within Santa Clara county, to the south, but high technology firms have in fact been a significant force in southeast San Mateo county as well.

${ }^{9}$ It is important to point out, however, that very few Aguilillans experienced the move into blue collar factory work that is normally suggested by the use of this term.
} 
These broad processes are clearly illustrated in the lives of Carlos and Antonio. Between the early 1940s and the early 1960s, their parents, Enrique and María, devoted themselves to building up a farming operation in a small rancho (or "hamlet") called La Pitaya. From this operation, they hoped to meet the immediate needs of their rapidly growing family. More ambitiously, they also hoped to provide each of their ten children with capital endowments large enough to let them stay in the area and continue making a living as petty producers. By the early 1960s, however, it was apparent that the farm would not yield enough resources to endow everyone, and so Enrique and María began encouraging their younger children to develop an alternative basis of support by continuing their education. Yet the income from the farm was soon unable to meet even the family's most immediate needs and so the older children turned to migration, hoping that the money they earned in the United States would enable them to both help their parents and finance the formation of their own operations.

So it was that Carlos, as the oldest son, left for the United States in 1966 and found his way to Redwood City, where he obtained work first as a dishwasher and later as an assistant cook. Antonio, the middle son, remained behind in school and, a few years later, managed-quite remarkably given his parents' poverty and lack of formal education-to gain admission to the state university where he began studying to be a doctor. In 1971, however, after two years in college, he dropped out and a year later migrated northwards to join his brother. Despite his advanced education, he ended up working first as a dishwasher and later as a janitor. Like his older brother, he entered the United States without papers.

Although Carlos and Antonio initially planned to stay only briefly, they became increasingly embroiled in life in the United States. Carlos married a Chicana, started having children with her and, through his marriage, obtained legal status. Antonio married a woman from Aguililla whom he had met in Redwood City, also started having children, and, in 1979, sought to legalize his status on the grounds that he had been in the country continuously for seven years without getting into trouble with the law or becoming a public charge. Significantly, in the early 1980s, both men purchased houses in the Redwood City area. By late 1984, when my fieldwork ended, they had clearly become long-term settlers. Carlos, by then 38 , had been in Redwood City eighteen years, and Antonio, 34, had been there twelve. More importantly, they had spent the great majority of their adult lives rehearsing the daily routines of proletarian labor.

\section{$\sim$ II $~$}

How should we understand their relationship to the context in which they lived? As I have already indicated, the dominant tendency over the last two 
decades has been to construe it in terms of adaptive responses to a new environment, one deemed to present people with a particular configuration of opportunities and constraints. But this tendency is problematical in several respects. It represents adult migrants as pre-formed subjects, it treats the settings in which they operate as too external-as a kind of maze or labyrinth laid out inertly before them; and it obscures both the cultural dimensions of contextual influence and the politics of daily life.

As an alternative, I would argue that we should view the experiences of Carlos and Antonio within an agonistic frame as active engagements with classrelated forms of discipline. That is, having set their lives in the context of proletarianization, we should appreciate that this involves not only politicoeconomic developments that undermine people's attachments to subsistence farming and throw them into wage-labor but also cultural pressures that work to make their daily habits and routines more consistent with the interests of capital. Moreover, we should recognize that, while these pressures are directed partly at people's behavior, they are also, and more profoundly, directed at their values and beliefs so that eventually they will regulate themselves (Thompson 1966). Put another way-one that enables a selective appropriation of poststructuralist insights - we should treat proletarianization as an integral part of broader processes involving the disciplinary production of classspecific subjects ( $c f$. Althusser 1972; Foucault 1979, 1983).

Such processes place a heavy emphasis on producing workers who, in contracting to sell their labor power as a commodity, are able to deliver it in a steady and dependable manner. They must turn up at the workplace regularly and punctually, be sober and rested so that the labor they provide is uniform and predictable, and use the time for which they are paid exclusively for work. But the production of "good" proletarians requires more than this. It has always involved the development of "good" citizens, people who devote their time outside work to individual and familial activities rather than to forms of collective interaction that might encourage concerted challenges to the status quo. And, increasingly since the $1920 \mathrm{~s}$, it has also involved the production of "good" consumers, people who not only spend freely but do so within approved circuits of capitalist exchange. To some extent, of course, these demands have been directed at everyone within the reach of consumer capitalism but, as I shall illustrate below, there are many ways in which both the demands themselves and the manner of their enforcement have varied along lines of class. Most notably, the habits and dispositions required of proletarian subjects have differed markedly from those considered appropriate for people in professional and managerial positions.

As Carlos and Antonio entered within the compass of such disciplinary mechanisms, they encountered challenges to many aspects of the way of life they had known in La Pitaya. It is impossible to cover all of these aspects here or to explore the differences between the pressures exerted in the United States and the similar but much less rigorous influences emerging in the municipio. 
I shall therefore focus on the workings of proletarian discipline in Redwood City and confine myself to just two areas of challenge: first, definitions of personal fulfillment and the ways in which it should be manifested, and second, ideas about the organization of space and the ways in which it should be used. Moreover, as I indicated earlier, I shall consider these issues specifically in relation to adult men.

The way of life that Carlos and Antonio knew as members of a farming family in La Pitaya defined fulfillment primarily in terms of the capacity to create and maintain independent, family-run operations, ideally based in land. In a setting that lacked overarching mechanisms of arbitration and protection and a cultural context that off-set an emphasis on family unity with a strong commitment to personal independence, such operations were constantly vulnerable to the unwanted intrusion of outsiders and to desertion from within. Correspondingly, the conduct of everyday life was organized to a large degree around attempts to maintain effective boundaries and regulate their crossing. Under these circumstances, both the family's house and the bodies of its members served as ready analogues of the collective property and, as such, were meant to exhibit and project a strong immunity to transgression. Houses were meant to present an austere and forbidding face to the outside world and, even on the inside, were meant to be unassuming in appearance. Bodies, particularly the bodies of the family's women, were meant to move demurely and to present an insistent modesty. Clothes were designed to cover the whole body and make-up was rarely used.

The standards and practices that Carlos and Antonio found pressed upon them in Redwood City were quite different. Fulfillment was associated with the capacity to earn well and to spend appropriately and, within this framework, people's houses and their bodies were treated as primary vehicles for the conspicuous expression of claims to success. Houses were meant to invite people's inspection and to serve as an effective medium for the display of prestigious consumer goods. And bodies, particularly female bodies, were meant to draw attention to an active participation in the costly world of fashion. For young Mexican women in the early 1980s, this meant wearing high-heeled shoes, plunging necklines, skin-tight jeans, and heavy make-up.

Regarding the organization of space, the way of life that Carlos and Antonio knew in La Pitaya gave primary emphasis to a familiar opposition between the domestic and the public. ${ }^{10} \mathrm{~A}$ bounded domestic realm, considered ordered, cooperative, and safe, was contrasted with an encompassing and unbounded public realm deemed chaotic, conflict-ridden, and dangerous.

${ }^{10}$ My analysis of spatial factors has been stimulated by the work of Yanagisako (1984) and by lectures given at Stanford University in 1980-81 by Jane Collier and the late Michelle Rosaldo. For a review of convergent attempts to explore the politics of space, see Soja (1989). A fuller account of the spatial dimensions of Aguilillan experience can be found in Rouse (in press). 
This opposition was, of course, both gendered and asymmetric, the domestic domain being associated with women and young children while the more highly valorized public domain was associated with adult men. In this context, women and young children were meant to stay within the domestic arena, either literally in their own homes or in places that were similarly bounded and protected such as the church and the houses of relatives and friends. Men, by contrast, were meant to move as freely as possible within the public realm and between the public and the domestic, furthering the interests of their family operations not only by working in the fields but also by meeting with other men so that they could reproduce vital social ties and shape the continuous negotiation of personal and familial reputations. In the process, as the heads of families, they were meant to regulate movement of all kinds across the boundaries of their property, mediate relationships between family members and the wider world, and ensure the maintenance of internal hierarchies that ascriptively privileged not just men over women but parents over children and old over young.

Once again, the standards and practices that Carlos and Antonio found pressed upon them in Redwood City were quite different. Space was organized in terms of a fundamental opposition between two equally bounded domains, home and the workplace (or its formal equivalent, the school), and these were distinguished not so much by their relative danger as by the idea that the workplace was the proper locus of socially valued labor, namely labor rewarded by a wage. Men's privileged access to the workplace and their privileged identity as primary wage-earners gave them greater authority than women, but the spatial implications of their authority were again quite different. Because women and children were construed as potential laborers, they too were meant to move outside the home. Women, as a crucial reserve, were meant to be given qualified access to the workplace and children, as workers in the making, were meant to move freely to and from school. Correspondingly, men were meant to let the state, as both a source of education and a regulator of domestic practices, have relatively unmediated access to the members of their families.

In this framework, then, proper movement for everyone involved a disciplined but "free" alternation between home and the workplace. Correspondingly, considerable stress was placed on avoiding a third realm made up of places such as street corners, bars, brothels, and gambling clubs, a realm commonly referred to as "the street." While attacks on the use of this realm were generally phrased in terms of immorality and personal danger, it is important to note that it was also an area in which people threatened to undermine their qualities as sober and rested workers, to meet in ways that might allow the development of collective challenges to the status quo, and to spend their money outside the approved circuits of capitalist exchange. If people did spend time neither at home nor at work, they were meant to do so primarily 
in malls, theme parks, and cinema complexes. These pleasure palaces of corporate capitalism, together constituting a fourth domain in the logic of spatial discipline, were often represented as privileged sites for large-scale gathering and collective interaction, equivalent in many ways to public settings in Aguililla. Yet they were in fact privately owned and carefully regulated arenas designed almost exclusively for individual and familial forms of use.

To some degree, of course, these arrangements and ideas were pressed on everyone in the Redwood City area. Yet, as Antonio knew from his advanced education and unfinished training as a doctor, this pressure also varied along lines of class and gender. Men subject to proletarian discipline were pressed to accept the constant scrutiny of supervisors, to see their labor power as a commodity measured in carefully calibrated units of time, and to distinguish sharply between the workplace as the site in which they delivered their labor power and the home as a locus of leisure and relaxation. "In contrast, professional and managerial workers, whether salaried or self-employed, were encouraged to operate independently, to think of their labor power as something delivered according to the demands of the task, and to accept a much more fluid relationship between the workplace and the home.

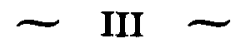

The influences that Carlos and Antonio encountered in Redwood City were not just politico-economic; they were also cultural. And the cultural context in which they operated was neither uniform nor neutral; it was differentiated along lines of class and served as a crucial medium of discipline. How did such discipline work?

In part, of course, proletarian discipline worked discursively through techniques aimed directly at the ways in which people evaluated and construed the world around them. Most notably, a multitude of messages in the mass media emphasized the fulfillment to be gained through appropriate consumption while attacking everything associated with the street. And although such messages were initially delivered almost exclusively in English, the introduction of a Spanish-language television channel and the steady growth of Spanish-language radio stations meant that, as the 1970s progressed, they were increasingly disseminated in Aguilillan's native tongue. Above all, however, proletarian discipline worked non-discursively through techniques directed primarily at the ways in which people acted. ${ }^{12}$ And, in this regard, the

11 The recent growth of industrial homework, performed almost exclusively by women, both illustrates and extends the ways in which the distinction between home and the workplace has been pressed differently on women and men. 87-90).

12 This distinction berween the discursive and the non-discursive follows Bourdieu (1977: 
most important sources of influence were the police and the INS (the Immigration and Naturalization Service, commonly referred to by Mexican migrants as "la migra").

The impact of these agencies was particularly significant regarding Aguilillans' use of space. Officers from the INS frequently approached people on the street and also patrolled many of the bars, dance halls, and recreational areas where Aguilillan men assembled. ${ }^{13}$ Those who were found to be undocumented were simply taken across the border to northern Mexico and, as a result, many were able to return within a few days. But the unpleasantness of temporary imprisonment, the costs involved in getting back to Redwood City, and the possible loss of valued and familiar jobs meant that many people without papers were cautious about attracting unnecessary attention. The local police also stopped Aguilillans on the street, especially those who were driving old and damaged cars or who were walking late at night in the wealthy neighborhoods surrounding Redwood City (something that their jobs as restaurant workers and office cleaners often obliged them to do). And they kept a close eye on many of the bars that migrant men frequented and on gatherings for illegal activities such as cock-fights and gambling. Even migrants who were doing nothing wrong found this kind of attention troubling. There was uncertainty about how the law would be applied and, for those without papers, the added fear that the police might hold them for collection by the INS. Influenced by the dangers that these two agencies posed, many Aguilillans moved as quickly and inconspicuously as they could between home and work and avoided any kind of large-scale gathering in public.

Yet the influences exerted by the INS and the police were not confined to constraints on people's use of space. In an indirect way, they also played an important part in encouraging Aguilillans to be good consumers. Given the fact that officers from both agencies paid most attention to people who looked out of place, there was a strong incentive for new arrivals to replace their cheap, Mexican clothes with a more expensive U.S. wardrobe and for settlers in general to find themselves good-looking cars and to move from barrack-like apartment buildings and multi-family homes into owner-occupied, single-family dwellings. At the same time, to the extent that Aguilillans were obliged by the activities of the two agencies to spend their leisure hours at home, they were given added reason to acquire sources of entertainment such as stereo systems, radios and televisions. Indeed, Aguilillans' susceptibility to the media was first dependent on the effective operation of forces that sought to turn them away from public, interpersonal forms of activity towards domestic settings.

Carlos and Antonio knew such disciplinary influences well. Both had been

${ }^{13}$ For a summary account of INS practices prior to passage of the Immigration Reform and Control Act of 1986, see West and Moore (1989:3-5). 
arrested and expelled by the INS and both had been challenged frequently by the police, especially during their early years in Redwood City. Moreover, the ways in which they talked suggested that the two agencies had played a significant part in changing their behavior. When I asked Carlos what he did for entertainment when he was first in Redwood City, he told me:

I didn't do anything . . . I couldn't even go to the movies ... My cousin said the migra was there ... I used to stay in the house all day long ... In the end I got a radio . . . There was a bar called "The Vietnam." I passed it every night but I never went in because they had fights there all the time and so the police would come... The police got very suspicious if you were on the streets after ten at night. They used to stop me on my way to the bus and ask me for my papers ... A friend started driving me home in his car, but he didn't have a license and we got stopped one time, so after that I started going home by taxi.

Antonio's observations were very similar:

The police ask for your papers if you don't have other identification and they take you off if you don't have them. They pick up people in the bars especially. When I was a bachelor, there were dances at St. Anthony's [the local Catholic church] but I didn't go because people said that the migma used to come ... Coming back from work, I was always scared because the migra used to stop you all the time ... so it was better to go home by car . . . Carlos used to take me or l'd get a taxi ... In the end I learned to drive and got a car of my own.

The police and the INS, then, affected settlers such as Carlos and Antonio not only as enforcers of law and order but also, and in some ways more powerfully, as agents of class-related discipline, encouraging them to become "good" proletarian subjects who would appear at work both sober and rested and who would use their earnings to further individual and familial interests through the rivalrous medium of conspicuous consumption.

It is important to point out, however, that the interventions of these agencies were not the only forms of non-discursive influence that Aguilillans faced. Behind them lay a series of ostensibly more neutral and benign processes that shaped the very terrain on which they were obliged to move and that influenced both the nature and efficacy of more immediate controls. Policies concerning zoning and the construction of low-income housing, for example, served to open up significant gaps for many Aguilillans between the places in which they could afford to live and the places in which they worked (Bernstein et al. 1977). And these gaps, in conjunction with the limited availability of public transportation, played a crucial role in increasing people's vulnerability to the attentions of the police and the INS as they moved to and from their work. Concomitantly, modernist forms of urban planning, apparently influenced by Le Corbusier's injunction to "kill the street," markedly reduced the availability of large, genuinely public spaces in which Aguilillans could con- 
gregate and, in so doing, channelled them to places such as bars and street corners that were much more readily monitored and controlled.

Operating in tandem, in fact, these different kinds of influence did not just shape the ways in which Aguilillans behaved. Through a complex process of habituation, they also worked indirectly to shape people's values and beliefs. By inscribing crucial oppositions in the area's landscape and by carefully regulating how this landscape was used, they worked to habituate people to desired patterns of action and, in so doing, encouraged them unconsciously to internalize the principles that guided this double structuring. ${ }^{14}$

Moreover, while in some respects this process affected everyone in the Redwood City area equally, its impact was also class-specific. The gap between home and work was generally much greater and more extreme for proletarian workers than for members of the professional-managerial elite, and the spatial practices of working people were much more carefully regulated than those of the upper middle classes. In the case of migrants like Carlos and Antonio, whose skin-color, lack of papers, and night-time work in wealthy neighborhoods made them especially vulnerable, the differences in regulatory attention were considerable. As Antonio once told me, "It's difficult, you know. You always have this fear that anyone you meet could be la migra."

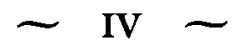

In the process of becoming long-term settlers, then, Carlos and Antonio came within the compass of disciplinary forces that insistently worked to change their whole way of life so that they would better serve the interests of capital. How did they respond?

When I began my discussions with the two men, they gave numerous indications that, after so many years of laboring for wages in the United States, they had not only adjusted their behavior to meet the requirements pressed upon them but had come to internalize the values and beliefs that these pressures worked to inculcate. Their compliance was indicated partly by the ways in which they talked about fulfillment. Both men emphasized their relative success as wage-earners and took considerable pride in the fact that they had been able to use their earnings effectively to benefit their families. Regarding their own conjugal families, they drew attention to the homes they had bought in Redwood City, to the work they had done to improve the outward appearance of these homes, and to the prestigious items such as televisions and stereos with which they had filled them. And, regarding their natal family

14 This argument builds on Bourdieu's account of "bodily hexis" and "the hysterisis effect" (1977:72ff.) but extends the workings of these non-discursive processes beyond childhood and beyond the confines of the house. 
back in Mexico, they described with equal pride how their material success and continued provision of remittances had been reflected, and made apparent to the wider community, in their family's move from La Pitaya into the municipio's one large town (also named Aguililla), in the large house that their parents had acquired there, in the consumer goods that adorned the house, and in the fashionable clothes that their youngest sister was able to wear while out in public.

Their internalization of these values and beliefs was also indicated by the way they talked about their work habits and their use of space. Both men spoke proudly of being good workers, people who were well-liked by their bosses for turning up on time and providing their labor in a steady and dependable manner. And they frequently drew attention to their careful avoidance of the diversions of the street. Echoing a refrain I heard numerous times during the course of my research, they both told me that they were the kind of people who went "from home to work and straight back home again."

As our conversations continued, however, I heard increasing evidence of a different response. To borrow-and rework-an image used by Robert Bellah and his colleagues in Habits of the Heart, Carlos and Antonio supplemented the "first language" I have described with a "second language" that articulated a markedly different set of attitudes and standards (Bellah et al. 1985). ${ }^{15}$ This second language was expressed most clearly in a series of criticisms that the two men directed at the kinds of lives they and their children were obliged to live in the United States.

Carlos and Antonio were particularly critical of the ways in which the rhythms and routines of proletarian labor impinged on their sense of independence. They complained quite often about having to labor subject to the dictates of the clock and the scrutiny of supervisors; they talked wistfully of the opportunities they had enjoyed in the municipio to "andar libre en los cerros," ("to move around freely in the mountains"); and they mentioned on several occasions their desire eventually to run their own operations rather than continue working for others. From their point of view, daily movement between home and the bounded, supervised realm of the workplace was a feminized kind of activity that threatened their self-worth as men.

They also criticized the forces that challenged their authority within the home. They disliked the fact that women and, above all, children were able to leave the house at will, and they were particularly critical of the ways in which the state could intervene between male heads of household and the women and children under their control. Both of them repeated stories, widely circulated among Aguilillans in Redwood City, which suggested that

15 Bellah et al. use the term "languages" to refer to "modes of moral discourse that include distinct vocabularies and characteristic patterns of moral reasoning" (1985:334). 
the spanking of a child or an argument between spouses could trigger the immediate intervention of the police. As Antonio told me on one occasion:

I love the children a lot and feel ashamed when I hit them. But occasionally it's necessary. It's important to have a little fear, in this case of God. Without it, people are more uncontrolled . . . I don't like the government poking its finger into family life over something like spanking a child. There's too much of an attempt to tell us how to live.

On another occasion, he complained:

Here the kids have lost their respect for their parents ... They can do whatever they like. If you try to stop them, they run away. If you try to spank them, they call the police. I'd like everyone to be here quietly in the house until they marry. But it's impossible to control the children ... At eighteen or so they want to leave and go off on their own.

The fears that Carlos and Antonio felt concerning influence over their children were also expressed in a series of criticisms directed at the nature of U.S. schooling. In part, they worried that the knowledge their children might acquire in school would upset domestic hierarchies by giving them too much knowledge too soon and by enabling them to act more effectively than their parents as mediators between the family and the wider world. More generally, they expressed doubts about whether U.S. schools were capable of providing the moral guidance they considered necessary. The teachers, they felt, were rarely strict enough and, as a result, proper hierarchies were undermined, leaving children exposed to the dangerous influence of their peers. In a phrase I heard repeatedly from Aguilillan parents, the two men claimed that children educated in such circumstances were especially vulnerable to "drogadicción y prostitución" ("drug addiction and prostitution"). Thus Carlos told me once, "I don't like the way that kids are raised in this country . . . They learn too much here about some things ... And they easily go onto drugs and all that stuff." Antonio's observations were similar:

The biggest problem with education here is the drugs ... The children begin to pay more attention to people of their own age than to their parents ... There is no control. In the United States, things are very liberal . . . freedom becomes hedonism ... I'd prefer to bring up the children in the house and teach them my own ideas of right and wrong. In school, here they learn different ways ... They say that young people are lost when they take drugs.

What is striking about these comments, I think, is not the revelation that Carlos and Antonio were dissatisfied with aspects of life in Redwood City. This is scarcely surprising among first generation settlers, or anyone else for that matter. Rather, it is the fact that the imagery they used was tied so closely to the normative and cognitive frames they had acquired in La Pitaya and, in particular, to the problems of boundary control that were associated with 
running a family operation. The criticisms that the brothers directed at threats to their domestic authority were articulated largely in terms of the dangerous permeability of domestic boundaries: women and children could leave without permission and agents of the state could intervene without regard to the mediations of the male head. And the concerns that they expressed about their children were crystallized in a pair of images emphasizing the equally dangerous permeability of bodies. Among Aguilillans, drugs were held to bring chaos to the ordered logic of the body and prostitution was thought to turn a woman loca ("crazy"), to rob her of the vital guidance provided by a regulating mind.

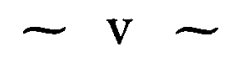

Thus, while Carlos' and Antonio's first language implied that they had changed their values and beliefs, their second suggested that they had, instead, retained their old ways of evaluating and interpreting the world, even after becoming long-term settlers in the United States. How should we construe the relationship between these languages? Which of them more accurately articulated their responses to the pressures that they faced?

There are many analysts who would treat the second language as relatively unimportant. As part of the wide-ranging reaction to studies that construed settlers as victims of cultural inertia, it has become common since the late 1960s for scholars to argue that people's references to their values and beliefs often contain the linguistic remnants of convictions they no longer hold and that, if their attitudes and standards are to be considered at all, they should be inferred primarily from what they do (or, more accurately if more complexly, from what they tell us about what they do)..$^{16}$

In the case of Carlos and Antonio, this trivializing of their second language seems encouraged by the fact that, in their daily routines, they rarely acted out the values and beliefs that it expressed. Yet I am inclined to treat this language more seriously, to see it as articulating attitudes and standards that continued to concern them. In principle, it is dangerous to imagine that people are free to express their desires and commitments fully in their actions, especially if they occupy subordinate positions (see Griswold del Castillo 1984). In practice, Carlos and Antonio expressed their criticisms with an intensity that suggested a continued investment in the principles on which they were based; and, rather than inertly holding on to established dispositions, they actively strove to maintain them, even in the face of concerted pressures to

16 See, for example, Baca Zinn (1979), Romano-V. (1970), and Vaca (1970b). A similar argument is made by Lamphere (1987) regarding Portuguese immigrants in New England. 
change. One way they did so was by regularly articulating the reservations I have described. Another was by telling stories at family gatherings and in other contexts about the years they had spent in the hamlet. Through affectionate descriptions of the time they had spent there and through admiring references to the ways in which their parents had behaved, they simultaneously preserved clear images of a different kind of life and reinforced their commitment to the values and beliefs that it expressed.

Given that these values and beliefs ran counter to the ones that proletarian discipline worked to inculcate, it seems reasonable to characterize Carlos and Antonio's second language as a language of resistance and, at the same time, to emphasize with this example that people challenge dominant systems not only in manifest acts but also by working hard to sustain compelling images of alternative possibilities. Indeed, it is tempting simply to invert the reading I have described and to privilege this second language while trivializing the first. There is certainly encouragement to do so from the burgeoning literature on everyday forms of popular resistance. In its more extreme versions, this literature suggests that people in subordinate positions continuously challenge the various forms of domination that they face and that apparent signs of compliance should be treated simply as forms of disguise used to mask the insistent pursuit of different goals (de Certeau 1984; Scott 1985). In the case of Carlos and Antonio, however, this alternative reading seems equally difficult to justify. As I suggested earlier, the two men gave every indication of having internalized many of the values and beliefs associated with being good proletarian workers, not only acting in the manner demanded of them but evaluating and interpreting much of their experience from the perspective that proletarian discipline worked to inculcate.

At the risk of seeming to offer a bland compromise, I would argue that we should take both languages seriously. From this perspective, Carlos and Antonio had neither abandoned the perspective they had learned in La Pitaya nor resolutely retained it to the exclusion of the new one pressed on them in Redwood City. Instead, they had broadened their cultural repertoire to include both. Yet this did not result in some ordered kind of synthesis. The two perspectives were in many ways quite contradictory and, although the implications of these contradictions could often be obscured, the basic tensions were always present, always capable of manifesting themselves in confusion and conflict. What the two men had developed was a cultural bifocality, a capacity to see the world alternately through quite different kinds of lenses.

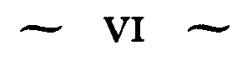

Carlos and Antonio were not alone. Many Aguilillan settlers in Redwood City developed a similar bifocality. How should we make sense of this contra- 
dictory vision? It is not enough, I believe, to challenge the neofunctionalist emphasis on adaptation. It is also necessary, as a final step, to reconsider the bipolarism that has so often been used to frame analyses of settlement. ${ }^{17}$

In its simplest form, the bipolar model assumes that migration takes place between territorially discriminable communities that retain their essential autonomy even as they grow more closely linked. More complexly and somewhat less explicitly, it also assumes that, in the long run, people are unable to remain involved in communities from a distance. Settlement is therefore seen as a process in which people inevitably reorient to their new locale, steadily transferring their home base, contextual focus, and locus of social activity from one place to another. Class transformation, when it is addressed, is deemed to involve a similarly clear and unambiguous shift. And the difference of degree between settlers and sojourners, based on length of stay, is also treated as a difference of kind, based on focus of orientation. Sojourners, it is suggested, remain oriented to the community they have left and therefore stay in the United States only briefly, while settlers, by reorienting to their new locale, tend increasingly towards permanent relocation. Thus the logic of bipolarism conduces readily to a binary framework that extends the basic distinction between mutually exclusive communities ("sending" and "receiving") into similar kinds of opposition between sojourners and settlers, migrants and immigrants, and the temporary and the permanent, while encouraging analysts to treat these oppositions as if they were identical. ${ }^{18}$

From this perspective, the bifocality I have described has been understood in three ways: as a combination of old dispositions too deeply inculcated to be shed and new ones adopted in reaction to the fresh environment; as a transitional state for people in the early stages of settlement; and as a product of contradictory forces intrinsic to life in the United States. Yet the assumptions central to the bipolar model and the readings it produces are too limiting. In particular, they are unable to deal with the ramifications of major changes in the workings of international capitalism, notably the reorganization of production on a transnational basis and capital's growing reliance since the late 1960s on strategies of flexible accumulation (Harvey 1989; Sassen 1988). Through the dialectical interplay between these broad material developments and the culturally mediated agency of the migrants themselves, new arrangements have emerged during the last two decades that the bipolar framework

${ }^{17}$ For a fuller version of the argument that follows, see Rouse (1991).

18 See, for example, Chavez (1988) and Cornelius (in press). This binarism is particularly common in analyses which argue that governments and capital gradually lose control of systems of temporary labor recruitment and that this loss of control is most clearly marked by steady shifts from sojourning to settlement and from settlement to permanent relocation (e.g., Piore 1979). It is manifest even in analyses which emphasize the development of translocational ties. See, for example, Dinerman (1982), Mines (1981), Reichert and Massey (1982), and Mines and Massey (1985). An early critique of such binarism can be found in Uzzell (1976). 
is unable to contain. An understanding of these arrangements and their genesis is crucial in the Aguilillan case.

From the beginnings of U.S.-bound migration in the early 1940s, people from the municipio were subject to contradictory influences. Mexican policies diverting capital from small-scale farming into industry and commercial agriculture, mounting U.S. demand for foreign labor, and marked differences between wage rates in the two countries encouraged many Aguilillans to migrate northwards. And, from the mid-1960s onwards, the growing need for workers in urban services and light assembly prompted increasing numbers to settle. But other factors discouraged settlers from feeling that they were making a simple, unidirectional shift.

Against the background of U.S. capital's general interest in minimizing its contributions to the reproduction costs of labor (Burawoy 1976; Meillassoux 1981), the selective but increasingly intense use of INS pressure and the growing restrictions on access to governmental sources of support made settlers uncomfortable about staying, especially when chronic illness, injury and aging or a downturn in the local economy reduced their attractiveness to employers. Meanwhile, the increasing bifurcation of the U.S. job market (SassenKoob 1982), steadily eroding the middle rungs between low-paid, nonunionized work and professional-managerial employment, made it difficult for settlers to see chances of upward mobility for themselves and, perhaps more significantly, for their children.

At the same time, most settlers remained committed to the goal of running their own operations and, while they saw little opportunity for realizing this ambition in the United States, a variety of factors encouraged them to feel that it was still a possibility back in Mexico, especially in the municipio. Given the area's remoteness and the lack of large tracts of readily irrigated land, agribusiness had not made the kinds of intervention that in other parts of Mexico had often led to the effective expropriation of local holdings; occasional government aid designed to prevent the complete collapse of subsistence agriculture had provided a limited buttress to local farming; and dollar remittances had managed to sustain many peasant operations that might otherwise have failed while stimulating new possibilities for petty entrepreneurship in areas such as construction, transportation and commerce. ${ }^{19}$

Quite a few settlers in Redwood City did in fact go back, even after lengthy stays in the United States. Some returned when they felt they had saved enough to fund an operation of their own; some when their children began to enter elementary school or when their eldest daughter reached puberty; and some when they retired. Many, exercising less choice in the matter, went

${ }^{19}$ An emphasis on the contradictory forces affecting Third World migrants is found most commonly in analyses guided by "articulation theory" (Kearney 1986). See, for example, Burawoy (1976), Cockcroft (1982), Kearney (1986), Kearney and Nagengast (1989), and Meillassoux (1981). 
back when they were expelled by the INS, when they could no longer deal with the pressure or when injury or chronic illness made it difficult to find work. By no means everyone returned for good. But people did go back. For Aguilillans, long-term settlement did not lead inexorably to permanent relocation. ${ }^{20}$

In these circumstances, many settlers remained oriented to the municipio even as they developed new involvements in the Redwood City area (Baca and Bryan 1983). People who had owned property before leaving generally held on to it, and those who were able to accumulate savings while abroad often used them to acquire houses and land back home. Many continued to contribute to enterprises in the municipio that were run by their parents and siblings, and those who had left operations in the hands of others often tried to preserve general control over their administration. In addition, many settlers maintained social ties with people who were based in the area, not only members of their immediate family but more distant relatives, friends and allies as well. The impetus to sustain these ties came in large part from the people left behind, for relatives and friends based in the United States could serve as vital sources of remittances and as key providers of support to those who followed in their footsteps. But many settlers also valued these relationships. Some relied on family and friends to look after the people and property they had left behind and most knew that, if they did return, they would be able to do so much more effectively if a solid network of support were already in place. Finally, given these varied attachments, most settlers worked hard to keep abreast of what was happening in the area, monitoring both general developments and particular events.

In the early years of Aguilillan migration, settlers found it difficult to sustain these involvements at a distance. But, from the late 1960s onwards, the obstacles were steadily diminished, especially for those in the Redwood City area. The emergence of a large and concentrated community that still attracted many short-term migrants enabled settlers to interact with people who were based in the municipio without having to return there. Growing access to affordable air travel and improvements to the transport system in Mexico dramatically reduced the time involved in moving back and forth, thus making it much easier for settlers both to visit briefly without surrendering homes and jobs in the United States and to reserve their trips for moments of urgent need. The construction of a secondary school in the town allowed parents to send their children back to the municipio for at least part of their education. And, most crucially, the growing availability of telephones in the area not only made it much easier for settlers to maintain ties and keep abreast of developments while they were away but also allowed them to participate

20 For examples of similar situations, see Baca and Bryan (1983), Fernández (1988), Massey et al. (1987), and Stuart and Kearney (1981). 
immediately in family celebrations and discussions about major decisions. Instead of leaving one community and reorienting to another, then, many settlers developed transnational involvements that encompassed both. While they lived in Redwood City, they were also living deep in western Mexico.

In this context, focus of orientation did not serve clearly to distinguish settlers from sojourners. Many Aguilillans long resident in Redwood City tried to maintain involvements in the municipio. At the same time, many shortterm migrants tried to develop involvements in Redwood City. Indeed, by the early 1980s, forms of orientation and patterns of movement varied immensely; they were rarely correlated in a simple way; and, more generally, the complexities of Aguilillan migration pressed well beyond the limits of familiar oppositions. Perhaps most notably, the basic distinction between the polar communities no longer held. Through constant movement back and forth, the energetic efforts to reproduce involvements across space, and the accompanying circulation of money, goods and services, the municipio, Redwood City and the other settlements in the United States had been woven together so tightly that, in an important sense, they had come to form a single community spanning the various locales, an arrangement I have referred to elsewhere as a "transnational migrant circuit." 21 It was the circuit as a whole that constituted the main arena in which Aguilillans developed and maintained social ties and the primary setting in which they orchestrated their lives. Moreover, while its continued existence depended on the efforts of those who actively reproduced their transnational connections, its workings exerted an effect on everyone who lived within its compass.

It is important to point out, however, that the circuit was not a homogeneous space. While life in Redwood City was dominated for Aguilillans by the rhythms and routines of proletarian labor, life in the municipio continued to be organized around petty production and its attendant cultural logic. Abstractly, this implied a certain coherence, the allocation of distinct but complementary activities to different sites within a single, integrated system. But experientially, for those immediately involved, it was an arrangement riven with contradictions. In mixing two quite different ways of making a living, Aguilillans found themselves obliged to balance two quite different ways of life.

It is in this context, I believe, that we should understand the bifocality developed by Carlos, Antonio and so many of their peers. Despite the tenor of my preliminary description, they were not undergoing a simple, unilinear shift from one country to another or from petty production to proletarian labor. Instead, they were becoming members of a transnational semiproletariat, caught chronically astride borders and class positions. All of the settlers in Redwood City inhabited a neighborhood dominated by this process; most

${ }^{21}$ See Rouse (1989a, 1991). Cf. Baca and Bryan (1983), Kearney (1986), Kearney and Nagengast (1989), Massey et al. (1987), and Mines (1981). 
envisaged futures for themselves and for their children that might involve returning to petty production in Mexico and that, more generally, would require the capacity to move effectively between these different worlds; and many participated actively in the municipio and in operations that were based there even as they worked for wages in the United States. Carlos and Antonio were not as fully involved as some. They did not own property in the municipio and they visited only occasionally. But they continued to contribute to the family operation headed by their parents and they thought quite often and in detail about going back. Their bifocalism stemmed not from transitional adjustments to a new locale, but from a chronic, contradictory transnationalism.

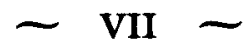

In this article, I have outlined a way of understanding the experiences of recent Mexican settlers that counters several trends long dominant (though not ubiquitous) in the literature. In particular, while stressing the need to restore a cultural dimension to the study of settlers' lives, I have challenged both the frequent use of bipolar models and the widespread emphasis on adaptation. Through an analysis focusing on migration from a single locale and, more narrowly, on the lives of just two men, I have tried to illustrate the merits of a perspective attentive to both class transformation and transnationalism. To conclude, I shall rearticulate the main points of my argument in a series of general suggestions relevant to the analysis of any given case.

First, we should insistently relate migration and settlement to the reproduction and transformation of class relations. This does not mean that settlers invariably undergo a process of proletarianization or, indeed, that they go through any kind of class transformation at all. It simply means that it is important to identify their class trajectories and, in particular, to be attentive to the difficulties that arise when people not only move between countries that are markedly different but also experience a major change in the ways in which they make a living.

Second, we should recognize that the reproduction and transformation of class relations is not simply an economic matter. It is also a cultural and political process in which people are subject to a wide array of disciplinary pressures working to shape their subjectivities in class-specific ways. For many people within the United States, these pressures simply reinforce existing tendencies and dispositions. For those settlers accustomed to making a living in ways quite different from the ones that they adopt in the United States, however, class-related discipline can represent a thoroughgoing challenge to their whole way of life.

Third, given the politically charged nature of the pressures that most settlers face, we should construe their responses not in the anodyne language of 
adaptation, coping, and fit but within an agonistic framework marked by terms such as compliance, accommodation, and resistance. We should not assume that discipline is automatically successful, but we should also avoid assuming that members of subordinate groups invariably resist. It is important to note, however, that, in dealing with class-related forms of discipline, settlers can often draw more directly than citizens on practical knowledge of an alternative way of life. Correspondingly, it is necessary to distinguish between the criticisms that settlers level at the United States as a country and the resentments that they express about the way of life associated with a particular way of making a living.

Fourth, we should analyze the nature of settlers' experiences from a perspective attentive to the emergence of transnational arrangements. These arrangements should be understood at a variety of levels. We should examine the local ramifications of the ways in which international capitalism has been reorganized on a transnational basis. We should consider whether, in a given case, the process of settlement has been accompanied by the emergence of a transnational circuit. And we should explore the extent to which individual settlers have developed and maintained transnational involvements. Neither circuits nor these kinds of involvement are inevitable features of migration under transnational conditions: there is, in fact, significant variation. But, to make sense of this variation, we must first possess a conceptual framework that allows us to identify it.

Finally, coming full circle, we should insistently relate transnational arrangements to the cultural politics of class relations. This is particularly important for those cases in which the multiple engagements that transnationalism involves link worlds associated with quite different ways of making a living. Under these conditions, the images of an alternative way of life which settlers draw upon in responding to class-related discipline affect them not simply with the cloying power of a formative past but as vital aspects of their existing lives and crucial guides to future possibilities.

\section{ACKNOWLEDGMENTS}

This article is based on research that was funded in large part by the InterAmerican Foundation. I began writing it while a visiting research fellow at the Center for U.S.-Mexican Studies at the University of California, San Diego in 1987-88 and completed it while a visiting scholar at the Center for Comparative Research in History, Society and Culture at the University of California, Davis in 1990-91. I am grateful to all three institutions for their support. Between the article's inception and its surrender, I presented various versions of the argument to Departments of Anthropology at Princeton, Michigan, Portland State, Emory, Boston, and SUNY Albany, and to the par- 
ticipants in the conference from which this collection derives. I would like to thank the many people in these settings who provided me with helpful questions and comments. I am also grateful to Eugenia Georges, Pierrette Hondagneu-Sotelo, and Sherry Ortner for careful readings of the text at various stages in its development. Finally, I would like to thank Nina Glick Schiller, Linda Basch, and Cristina Blanc-Szanton for their immense efforts as organizers of the initial conference and as editors of the present volume.

\section{REFERENCES CITED}

Achor, Shirley

1978 Mexican Americans in a Dallas barrio. Tucson: University of Arizona Press. Althusser, Louis

1972 Ideology and ideological state apparatuses (Notes Towards an Investigation). In Lenin and philosophy and other essays, translated by Ben Brewster. New York: Monthly Review Press. Pp. 127-186.

Alvarez, Robert R., Jr.

1987 Familia: Mignation and adaptation in Baja and Alta California, 1800-1975. Berkeley: University of California Press.

Alvirez, David and Frank D. Bean

1976 The Mexican American family. In Ethnic families in America: Patterns and variations, edited by Charles H. Mindel and Robert W. Habenstein. New York: Elsevier. Pp. 271-292.

Baca, Reynaldo and Dexter Bryan

1983 The "assimilation" of unauthorized Mexican workers: Another social science fiction. Hispanic Journal of Behavional Sciences 5(1):1-20.

Baca Zinn, Maxine

1979 Chicano family research: Conceptual distortions and alternative directions. Journal of Ethnic Studies 7(3):59-71.

Bellah, Robert N., Richard Madsen, William M. Sullivan, Ann Swidler, and Steven M. Tipton

1985 Habits of the heart: Individualism and commitment in American life. Berkeley: University of California Press.

Bernstein, Alan, Bob de Grasse, Rachael Grossman, Chris Paine, and Lenny Siegel

1977 Silicon Valley: Paradise or paradox? The impact of high technology industry on Santa

Bourdieu, Pierre Clara Valley. Mountain View, CA: Pacific Studies Center.

1977 Outline of a theory of practice, translated by Richard Nice. Cambridge: Cambridge University Press.

Burawoy, Michael

1976 The functions and reproduction of migrant labor: Comparative material from South Africa and the United States. American Journal of Sociology 81(5): 1050-1087.

Butterworth, Douglas $S$.

1962 A study of the urbanization process among Mixtec migrants from Tilaltongo in Mexico. América Indigena 22:257-274.

Carlos, Manuel L.

1975 Traditional and modern forms of compadrazgo among Mexicans and 
Chavez, Leo R.

Mexican-Americans: A survey of continuities and changes. Atti del XL Congresso Internazionale Degli Americanisti, Roma-Genowa, 1972 (Vol. 3). Genoa: Tilgher. Pp. 469-483.

1988 Settlers and sojourners: The case of Mexicans in the United States. Human Organization 47(2):95-107.

Cockcroft, James D.

1982 Mexico: Class formation, capital accumulation, and the state. New York: Monthly Review Press.

Cornelius, Wayne A.

1979 Mexican and Caribbean migration to the United States: The state of current knowledge and recommendations for future research. La Jolla, CA: Program in United States-Mexican Studies.

in press From sojourners to settlers: The changing profile of Mexican migration to the United States. In U.S. Mexican relations: Labor market interdependence, edited by Jorge Bustamante, Raul Hinojosa and Clark Reynolds. Stanford, CA: Stanford University Press.

de Certeau, Michel

1984 The practice of everyday life, translated by Steven F. Rendell. Berkeley: University of California Press.

Dinerman, Ina $\mathrm{R}$.

1978 Patterns of adaptation among households of U.S.-bound migrants from Michoacán, Mexico. International Migration Review 12(4):485-501.

1982 Migrants and stay-at-homes: $A$ comparative study of rural migration from $\mathrm{Mi}$ choacán, Mexico. La Jolla, CA: Center for U.S.-Mexican Studies.

Fernández, Celestino

1988 Migración hacía los Estados Unidos: Caso Santa Inés, Michoacán. In Migración en el occidente de México, edited by Gustavo López Castro and Sergio Pardo Galván. Zamora, Michoacán: El Colegio de Michoacán. Pp. 113-124.

Foucault, Michel

1979 Discipline and punish: The birth of the prison, translated by Alan Sheridan. New York: Vintage Books.

1983 The history of sexuality. Volume I: An introduction, translated by Robert Hurley. New York: Vintage Books.

Graves, Nancy B. and Theodore D. Graves

1974 Adaptive strategies in urban migration. Annual Review of Antbropology 3: $117-151$.

Griswold del Castillo, Richard

1984 La familia: Chicano families in the urban Southwest, 1848 to the present. Notre Dame, IN: University of Notre Dame Press.

Harvey, David

1989 The condition of postmodernity: An enquiry into the origins of cultural change. Oxford: Basil Blackwell.

Hendricks, Janet and Arthur D. Murphy

1981 From poverty to poverty: The adaptations of young migrant households in Oaxaca, Mexico. Urban Anthropology 10(1):53-70.

Horowitz, Ruth

1983 Honor and the American dream: Culture and identity in a Chicano community. New Brunswick, NJ: Rutgers University Press.

Humphrey, Norman D.

1944 The changing structure of the Detroit Mexican family: An index of acculruration. American Sociological Roview 9(6):622-626. 
Kearney, Michael

1986 From the invisible hand to visible feet: Anthropological studies of migration and development. Annual Review of Antbropology 15:331-361.

Kearney, Michael and Carole Nagengast

1989 Anthropological perspectives on transnational communities in rural California. Working Paper 3, Working Group on Farm Labor and Rural Poverty. Davis, CA: California Institute for Rural Studies.

Kemper, Robert V.

1977 Migration and adaptation: Tzintzuntzan peasants in Mexico City. Beverly Hills, CA: Sage Publications.

1979 Frontiers in migration: From culturalism to historical structuralism in the study of Mexico-U.S. Migration. In Migration across frontiers: Mexico and the United States, edited by Fernando Cámara and Robert V. Kemper. Albany: State University of New York.

Lamphere, Louise

1987 From working daughters to working mothers: Immignant women in a New England industrial community. Ithaca, NY: Cornell University Press.

Lewis, Oscar

1952 Urbanization without breakdown. Scientific Monthly 75:31-41.

Lomnitz, Larissa A.

1976 An ecological model for migration studies. Rice University Studies 62(3): 13l-146.

1977 Networks and marginality: Life in a Mexican shantytown, translated by Cinna Lomnitz. New York: Academic Press.

Madsen, William

1964 The Mexican Americans of South Texas. New York: Holt, Rinehart \& Winston.

Massey, Douglas S., Rafael Alarcón, Jorge Durand, and Humberto González

1987 Return to Aztlan: The social process of international migration from western Mexico. Berkeley: University of California Press.

Meillassoux, Claude

1981 Maidens, meal and money: Capitalism and the domestic community. Cambridge: Cambridge University Press.

Mines, Richard

1981 Developing a community tradition of migration: A field study in rural Zacatecas, Mexico, and in California settlement areas. La Jolla, CA: Program in United States-Mexican Studies.

Mines, Richard and Douglas S. Massey

1985 Patterns of migration to the United States from two Mexican communities. Latin American Research Review 20(2):104-123.

Piore, Michael

1979 Binds of passage: Mignant labor and industrial societies. Cambridge: Cambridge University Press.

Ramírez, Ignacio

1988 Aguililla: Todo un pueblo dedicado al cultivo de amapola y mariguana. Proceso 599:10-13.

Reding, Andrew

1990 Drugs, politics and reform in Mexico. $Z$ Magazine 3(12):88-93.

Reichert, Joshua S. and Douglas S. Massey

1982 Guestworker programs: Evidence from Europe and the United States and some implications for U.S. Policy. Population Research and Policy Review 1: $1-17$. 
Roberts, Bryan

1974 The interrelationships of city and provinces in Peru and Guatemala. Latin American Urban Research 4:207-235.

Romano-V., Octavio I.

1968 The anthropology and sociology of the Mexican-Americans: The distortion of Mexican-American history. A review essay. El Grito 2:13-26.

1970 Social science, objectivity and the Chicanos. El Grito 4:4-16.

Rosaldo, Renato J.

1985 Chicano studies, 1970-1984. Annual Review of Anthropology 14: 405-427.

Rouse, Roger

1989a Mexican migration to the United States: Family relations in the development of a transnational migrant circuit. Ph.D. dissertation, Department of Anthropology, Stanford University.

$1989 \mathrm{~b}$ Migration and the politics of family life: Divergent projects and rhetorical strategies in a Mexican transnational migrant community. Ms. Department of Anthropology, University of Michigan, Ann Arbor.

1991 Mexican migration and the social space of postmodernism. Diaspora $1(1)$ : 8-23.

in press Men in space: Class relations and the politics of urban form among Mexican migrants in the United States. In Culture, power, place: Explorations in critical anthropology, edited by Roger Rouse, James Ferguson and Akhil Gupta. Boulder, CO: Westview Press.

Rubel, Arthur J.

1966 Across the tracks: Mexican-Americans in a Texas city. Austin: University of Texas Press.

Sassen, Saskia

1988 Mobility of capital and labor: A study in international investment and labor flow. Cambridge: Cambridge University Press.

Sassen-Koob, Saskia

1982 Recomposition and peripheralization at the core. Contemporary Marxism 5 : 88-100.

Scott, James C.

1985 Weapons of the weak: Everyday forms of peasant resistance. New Haven, CT: Yale University Press.

Soja, Edward W.

1989 Postmodern geographies: The reassertion of space in critical social theory. London: Verso.

Stuart, James and Michael Kearney

1981 Causes and effects of agricultural labor migration from the Mixteca of Oaxaca to California. La Jolla, CA: Program in United States-Mexican Studies.

Thompson, Edward P.

1966 The making of the English working class. New York: Random House.

Thurston, Richard G.

1974 Urbanization and sociocultural change in a Mexican-American enclave. San Francisco: R \& E Associates.

Ugalde, Antonio with Leslic Olson, David Schers, and Miguel Von Hoegen

1974 The urbanization process of a poor Mexican neighborhood. Austin: Institute of Latin American Studies, University of Texas.

Uzzell, Douglas

1976 Ethnography of migration: Breaking out of the bi-polar myth. Rice University Studies 62:45-54. 
Vaca, Nick C.

1970a The Mexican-American in the social sciences, 1912-1970. Part I: 1912-1935. El Grito 3:3-24.

1970b The Mexican-American in the social sciences, 1912-1970. Part II: 19361970. El Grito 4:17-51.

West, Martin and Erin Moore

1989 Undocumented workers in the United States and South Africa: A comparative study of changing social control. Human Organization 48(1):1-10.

Williams, Raymond

1977 Marxism and literature. Oxford: Oxford University Press.

Wood, Charles $\mathrm{H}$.

1981 Structural changes and household strategies: A conceptual framework for the study of rural migration. Human Organization 40(4):338-344.

Yanagisako, Sylvia J.

1984 Explicating residence: A cultural analysis of changing households among Japanese-Americans. In Households: Comparative and bistorical studies of the domestic group, edited by Robert McC. Netting, Richard R. Wilk and Eric J. Arnould. Berkeley: University of California Press. Pp. 330-352. 